\title{
Interphase Mass Transfer of the High Velocity Bubbling Fluidization Regime
}

\author{
Jean Saayman $^{\mathbf{1}^{*}}$ and Willie Nicol ${ }^{\mathbf{1}}$ \\ ${ }^{1}$ Department of Chemical Engineering \\ University of Pretoria - Main Campus \\ Corner Lynwood Rd \& Roper St \\ Hatfield \\ Pretoria \\ 0002 \\ South Africa \\ * Corresponding author: Jean Saayman \\ Email: $\quad$ jeansaayman@gmail.com \\ Phone: $\quad$ +2784 $\quad$ 2134079 \\ Postal Address: $\quad$ Dr. Jean Saayman \\ Department of Chemical Engineering \\ University of Pretoria - Main Campus \\ Corner Lynwood Rd \& Roper St \\ Hatfield \\ 0002 \\ South Africa
}

\begin{abstract}
Gas-solid fluidization experiments were performed in two separate experimental setups with similar dimensions. Fast X-Ray Tomography (XRT) was used in setup 1, while ozone decomposition experiments were performed in setup 2. Packing and operation characteristics for the two setups were close to identical. The hydrodynamic measurements from the XRT acquisitions were used to evaluate the interphase mass transfer characteristics obtained from the ozone decomposition results. Superficial velocities $\left(U_{0}\right)$ spanning the bubbling up to the onset of the turbulent regime $\left(U_{c}\right)$ were employed. Traditional specific interphase mass transfer $\left(k_{b e}\right)$ correlations are based on incipiently fluidized beds; however, results suggested that a distinction should be made between the low-interaction bubbling regime and the highinteraction bubbling regime. A change in mass transfer behaviour occurred around a $U_{0} / U_{c}$ value of 0.25 . An empirical correlation for $k_{b e}$ of the high-interaction bubbling regime is
\end{abstract}


proposed. The correlation gave the best fit for the entire velocity range with an average error of $8 \%$, although it is not recommended for $U_{d} U_{c}<0.17$. It was observed that the classical approach of penetration theory for interphase mass transfer, performed exceptionally well at low velocities $\left(U_{0} / U_{c}<0.34\right)$.

KEYWORDS: Fluidization hydrodynamics; Ozone decomposition reaction; X-ray tomography; Interphase mass transfer.

\section{Introduction}

Catalytic Gas-Solid Fluidized Bed Reactors (FBRs) have been studied and used for over six decades. From novel laboratory demonstrations [1] to performing nanoparticle coatings [2], to being at the heart of large petrochemical companies $[3,4]$, these reactors have many uses. From an engineering point of view, advantages include: efficient solids mixing, good gas-solid contacting and low pressure drop. A wealth of understanding of the hydrodynamics of FBRs and their effects on reactor performance has been gained, although there are numerous areas where fundamental understanding is lacking; examples include modelling, the applicability of two phase theory and the accuracy of interphase mass transfer correlation for different regimes. Many studies mainly focus on either a specific hydrodynamic parameter or the reactor performance. Few studies have followed an integrated approach, which creates difficulties in modelling an FBR. Depending on the operating velocity $\left(U_{0}\right)$ several regimes exist in FBRs, most commonly used being the bubbling, turbulent or fast fluidization regimes. Each regime is characterized by its own hydrodynamic behaviours. The bubbling and fast fluidization regimes have enjoyed much academic attention due to the distinctness of the bubbles and the core annulus, respectively. The turbulent regime has better gas-solids contacting than the bubbling regime without the high solids circulation of the fast fluidization regime. These reasons make the turbulent regime a popular choice for industry. Commercial examples of turbulent reactors include FCC regenerators, zinc sulphide roasters and Mobil MTG, acrylonitrile, maleic anhydride, phthalic anhydride and ethylene dichloride reactors. Despite the turbulent regime being popular in industry, it has not received as much attention as the bubbling or fast fluidization regimes. [5]

Based on observations of incipiently fluidized bubbling beds, the need for hydrodynamic descriptions of two-phase behaviour arose. The earliest well-known published works on the 
matter were those of Rowe and Partridge [6,7] and Davidson and Harrison [8-10]. The concept was developed further and gas exchange between the phases was explored [11-16]. Ultimately, leaders in the field such as Kunii, Levenspiel and Grace proposed reactor models based on the theory [17-22]. Generally, these reactor models and the two-phase theory best describe the hydrodynamic behaviour of bubbling fluidized beds [23-26]. The theory entails that most of the gas reagents are contained in a lean, solids/catalyst-deprived phase that bubbles though a dense, solids-rich (emulsion) phase. This closely resembles the physical phenomena in the FBR. Since most of the gas throughput is present in the lean phase, the movement of gas into and out of the emulsion phase often dictates the performance of an FBR. Therefore the description of the interphase mass transfer becomes one of the crucial modelling variables. Most correlations for this transfer are derived on the basis of lowvelocity/interaction bubbling regime behaviour with small $U_{0} / U_{c}$ values of 0.02 , where $U_{c}$ is the onset velocity of the turbulent regime. In this low $U_{0} / U_{c}$ regime the bubbles have nearideal geometries and low interactions with each other. Despite the success of these models at lower velocities, the transfer correlations are not suited for higher velocity operations [25,2729].

Few attempts have been made to adapt interphase mass transfer correlations for the higher velocity bubbling regime or turbulent regime [30]. Studies have been conducted where the performance of existing mass transfer correlation have been investigated. Using inert tracergas experiments $\mathrm{Wu}$ and Agarwal looked at the effects of temperature in a fluidized bed [27]. This study was done in a $127 \mathrm{~mm}$ ID column with a bed of particles which was incipiently fluidized using pure nitrogen gas, while single argon gas bubbles were injected near the distributor at the bottom of the bed. These Argon containing bubbles travelled upwards to the top of the bed where a tube extracted a sample of the bubble's gas as the bubble passed the tube. Experiments were conducted using particles from $264 \mu \mathrm{m}$ to $463 \mu \mathrm{m}$ and at temperatures of 298 K, 423 K, $573 \mathrm{~K}$ and $773 \mathrm{~K}$. The Sit and Grace [16] and Davidson and Harrison [9] correlations were tested. Wu and Agarwal [27] found that the Sit and Grace correlation performed better, but in some cases was not ideal. They incorporated a correction factor for the convection term.

When it comes to reactions in a freely bubbling bed, concentration gradients steepen due to reaction in the cloud phase and bubble interaction starts playing a big role. Thompson et al. [25] used the data of Sun [28] in a new transitional two-phase model. They had to incorporate a correction factor to the Sit and Grace [16] correlation to fit the data. This might be due to the effect of the probabilistic transition factor present in the model. Campos et al. [29] 
performed reactor performance experiments in a coke combustor at $1223 \mathrm{~K}$ and inferred mass transfer using two-phase theory. The researchers tested the overall mass transfer correlation of Kunii and Levenspiel and found that the correlations far over-predicted mass transfer. Although, Kunii and Levenspiel warn that the overall mass transfer correlation, which is based on a two-step mass transfer process and a three-phase model, cannot be reduced to a two-phase model for reacting systems [31]. The book of Kunii and Levenspiel [31] is also recommended for a general overview of the field of fluidization.

An integrated approach combining hydrodynamics and reactor performance is followed in this study with the focus on the upper end of the bubbling regime and the start of the turbulent regime. The aim is to investigate which theories in the literature are applicable and which do not hold in a more "violently" bubbling bed. This is achieved by performing indepth hydrodynamic investigations into a reactive fluidized bed. All experiments are executed at atmospheric conditions using sand particles and two setups. A reaction setup and an advanced X-Ray Tomography (XRT) setup both equipped with pressure sensors are used. The same particles and column diameter are implemented in both setups. Detailed results of the XRT-obtained hydrodynamic insights are reported in previously published work and will be incorporated in this work [32,33]. All reaction experiments are conducted in a $14 \mathrm{~cm}$ column using the ozone decomposition reaction and spanning the bubbling to turbulent onset regimes $\left(0.09<U_{0} / U_{c}<1.11\right)$. Reactor performance is quantified using a basic two-phase model to obtain the apparent overall mass transfer.

\section{Experimental}

The XRT setup was a $1.4 \mathrm{~m}$ high acrylic column, $140 \mathrm{~mm}$ in diameter. Three X-ray sources were positioned around the column as well as three detector arrays opposite each source. Each detector array contained two rows of 32 detectors. This configuration allowed for advanced cross sectional hydrodynamics measurements and tomographic reconstructions. Details on this setup, the measurement techniques and results are previously published $[32,33]$. The reaction setup was a $140 \mathrm{~mm}$ (ID) acrylic column with a height of $5.5 \mathrm{~m}$, which was used to conduct reaction performance experiments. The ozone decomposition reaction was implemented to gauge the FBR's reactor performance. This reaction is popular in FBR experiments due to its first order nature and the small quantities required for analysis resulting in negligible volume change and heat generation [1,15,28,34]. A third packed bed test reactor, with ideal plug flow behaviour and no hydrodynamic influences, was used solely 
to determine the first order rate constant of the catalyst being utilized in the FBR reaction setup. Two cyclones in series were used to return entrained solids to the bed. The primary cyclone was a volute cyclone in order to handle high solids loading and the secondary cyclone was a tangential cyclone. An exhaust system with a solids filter bag container was installed after the cyclones to remove any remaining solids safely and to dispose of ozonecontaining air via a stack. The filter bags were weighed before and after experiments and solids losses were found to be negligible. Absolute pressure transmitters were installed at the distributor, $0.2 \mathrm{~m}$ from the distributor and $0.4 \mathrm{~m}$ from the distributor. Figure 1 schematically shows the equipment setup. The fluidizing air supply was dosed with ozone and inlet ozone samples were continuously drawn from the centre of the plenum chamber, $50 \mathrm{~mm}$ below the distributor. Outlet samples were taken at a height of $4.2 \mathrm{~m}$ above the distributor. Catalyst activity was determined in a $16.4 \mathrm{~mm}$ (ID) test reactor with plug flow behaviour. To ensure the catalyst samples were not exposed to an atmosphere other than that inside the FBR the test reactor could be loaded using the fluid nature of a fluidized bed and tapping catalyst directly from the FBR. Both the FBR and the test reactor were supplied with the same ozonedosed air. The test reactor was designed to detach safely from the FBR, to weigh and empty the loaded catalyst sample. The setup and equipment is discussed in more detail elsewhere [35].

To activate sand for ozone decomposition, the particles require treatment. Iron oxide is consequently impregnated onto the particles. The method of Fan et al. was adopted $[34,36]$. The particles are mixed into a stirring solution of $10 \mathrm{wt} . \%$ ferric nitrate. After $1 \mathrm{~h}$ the stirrer is switched off and the solids are allowed to settle out for $15 \mathrm{~min}$. Excess solution is decanted and the sludge placed in an oven for $12 \mathrm{~h}$, resulting in dried solid chunks. These chunks are ground and sieved to the correct size fraction. Lastly, the batch is placed in a furnace at $475{ }^{\circ} \mathrm{C}$ to calcinate the impregnated ferric nitrate to ferric oxide. The calcination reaction is as follows:

$$
\mathrm{Fe}\left(\mathrm{NO}_{3}\right)_{3} \cdot \mathrm{nH}_{2} \mathrm{O} \stackrel{\geq 370^{\circ} \mathrm{C}}{\longrightarrow} \frac{1}{2} \mathrm{Fe}_{2} \mathrm{O}_{3}+3 \mathrm{NO}_{2}+\frac{3}{4} \mathrm{O}_{2}+\mathrm{nH}_{2} \mathrm{O}
$$

As shown, $\mathrm{NO}_{2}$ gas is released during the calcination process. When no $\mathrm{NO}_{2}$ is detected, the reaction has reached completion; this takes approximately $2.5 \mathrm{~h}$. 


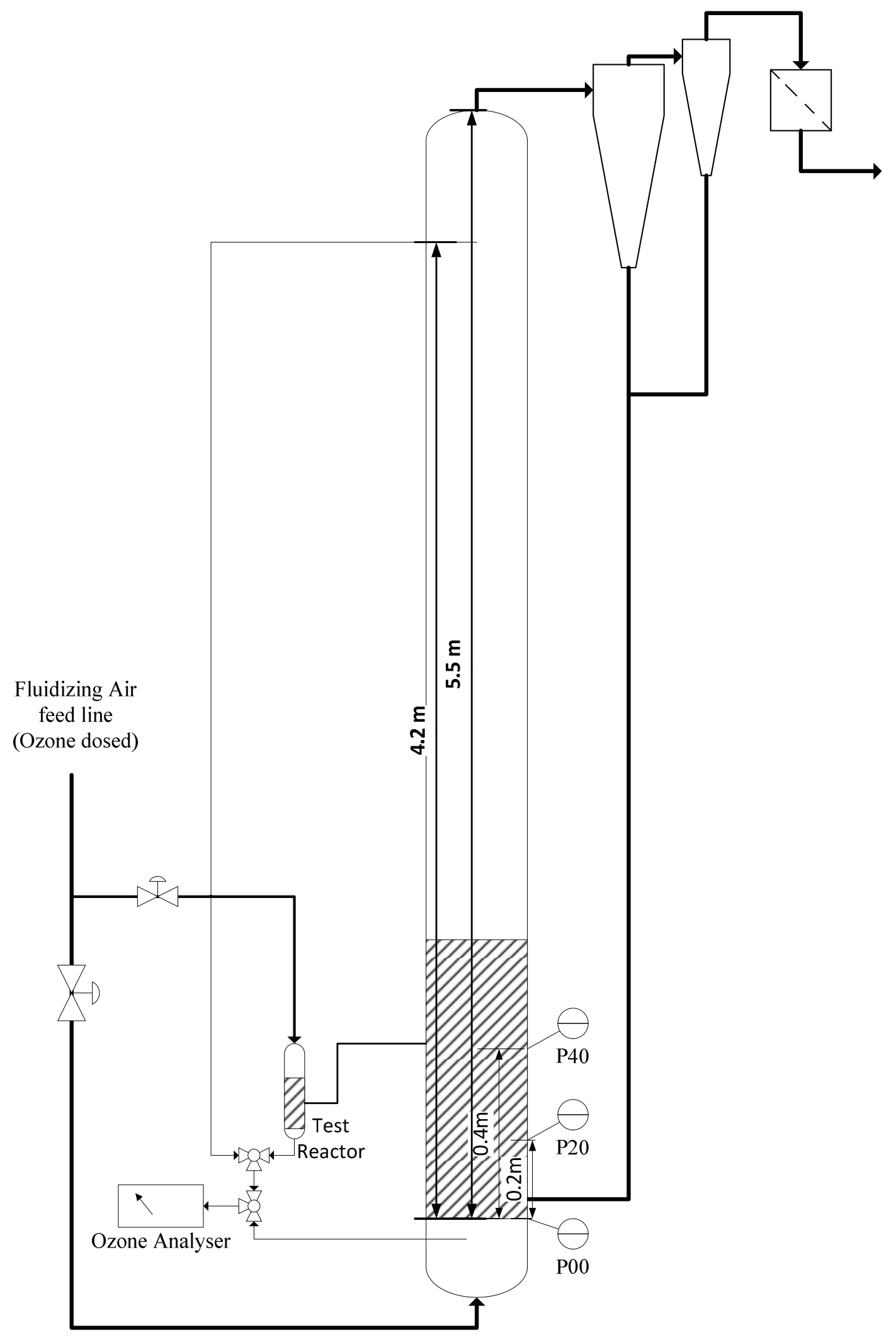

Figure 1: Reactor experimental setup and schematic drawing. 


\subsection{Method}

Before experiments were started, first-order behaviour was confirmed using the small test reactor. Catalyst was loaded into the test reactor and the conversion determined at different flow rates and inlet ozone concentrations. These measurements were made in a relatively short period. A first-order reaction rate Plug Flow Reactor (PFR) model predicted the conversion results accurately, as shown in Figure 2 . The first order rate constant $\left(k_{R}\right)$ was $15 \mathrm{~s}^{-1}$ during the verification experiment.

During experiments the test reactor was used to check the activity of the catalyst inside the FBR. A sample of the bed was taken and the catalytic activity was determined for each measurement of the FBR's conversion. The FBR and test reactor were run in parallel. Care was taken to sample catalyst out of the FBR into the test reactor without exposing the sample to a different atmosphere. Both reactors were supplied with the same feed gas and advantage was taken of the liquid nature of fluidization to "tap" catalyst directly into the test reactor. In this way variations in the bed activity are accounted for, instead of trying to stabilize the catalyst activity. During operations the test reactor was run at a single velocity since firstorder behaviour was known. After each FBR conversion reading, a catalyst sample was taken and the activity determined within $5 \mathrm{~min}$. In this manner a pseudo-instantaneous catalyst activity was obtained. The detachable design of the test reactor made catalyst unloading and weighing between measurements possible.

The following procedure was completed to determine the FBR's conversion. The FBR was set to a specific superficial velocity. The outlet gas-sampling probe was operated in reverse to backwash the filter. High-pressure air from the plenum chamber was used. After the filter had been cleaned, the FBR's outlet concentration was measured for 90 s. Sampling was then switched to the plenum chamber to determine the inlet concentration for $90 \mathrm{~s}$. Lastly, a fresh catalyst sample was loaded into the test reactor and the reaction rate constant determined within $5 \mathrm{~min}$. In a single experimental run this procedure was repeated at 11 different superficial velocities. Three experimental runs were conducted with different means of velocity sequences: low to high; high to low and a random selection.

The FBR was loaded with $13.5 \mathrm{~kg}$ of activated sand which resulted in a bed height of $520 \mathrm{~mm}$. It was determined that $14 \mathrm{wt} . \%$ of catalyst was in the return system. For the range of superficial gas velocities studied, the settled bed height did not change significantly. The amount of catalyst in the return system therefore remained fairly constant. System properties are reported in Table 1. 
Table 1: Catalyst and fluidizing medium properties.

\begin{tabular}{l|c}
\hline & System properties \\
\hline$\rho_{p}\left(\mathrm{~kg} / \mathrm{m}^{3}\right)$ & 2450 \\
$\rho_{b}\left(\mathrm{~kg} / \mathrm{m}^{3}\right)$ & 1450 \\
$\overline{d_{p}}(\mu \mathrm{m})$ & 101 \\
Geldart & $\mathrm{B}$ \\
$U_{m f}(\mathrm{~mm} / \mathrm{s})$ & 9.1 \\
$\varepsilon_{m f}$ & 0.41 \\
$\mu_{g}(\mathrm{~Pa} . \mathrm{s})$ & $18 \times 10^{-6}$ \\
$\rho_{g}\left(\mathrm{~kg} / \mathrm{m}^{3}\right)$ & 1.2 \\
$D_{m}\left(\mathrm{~m}^{2} / \mathrm{s}\right)$ & $20 \times 10^{-6}$ \\
\hline
\end{tabular}




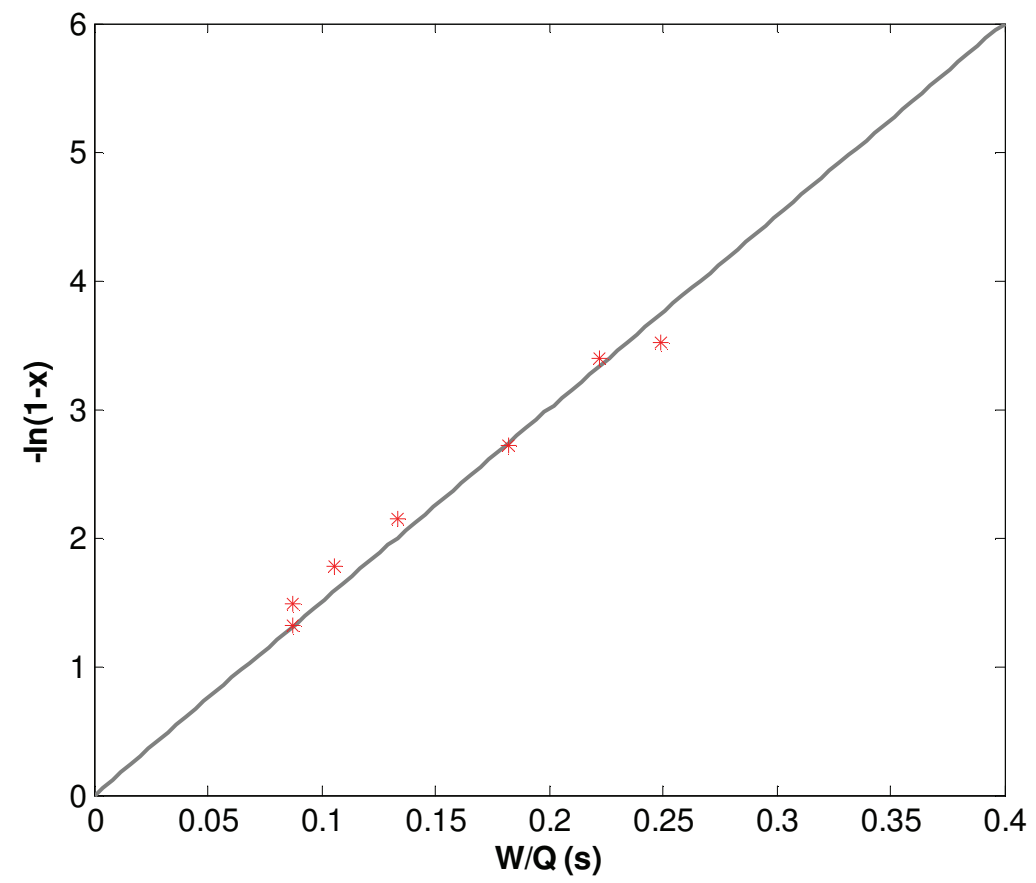

Figure 2: Confirmation of first-order behaviour. The linear line is a first-order PFR model with $\mathbf{k R}=15 \mathrm{~s}-1$. 


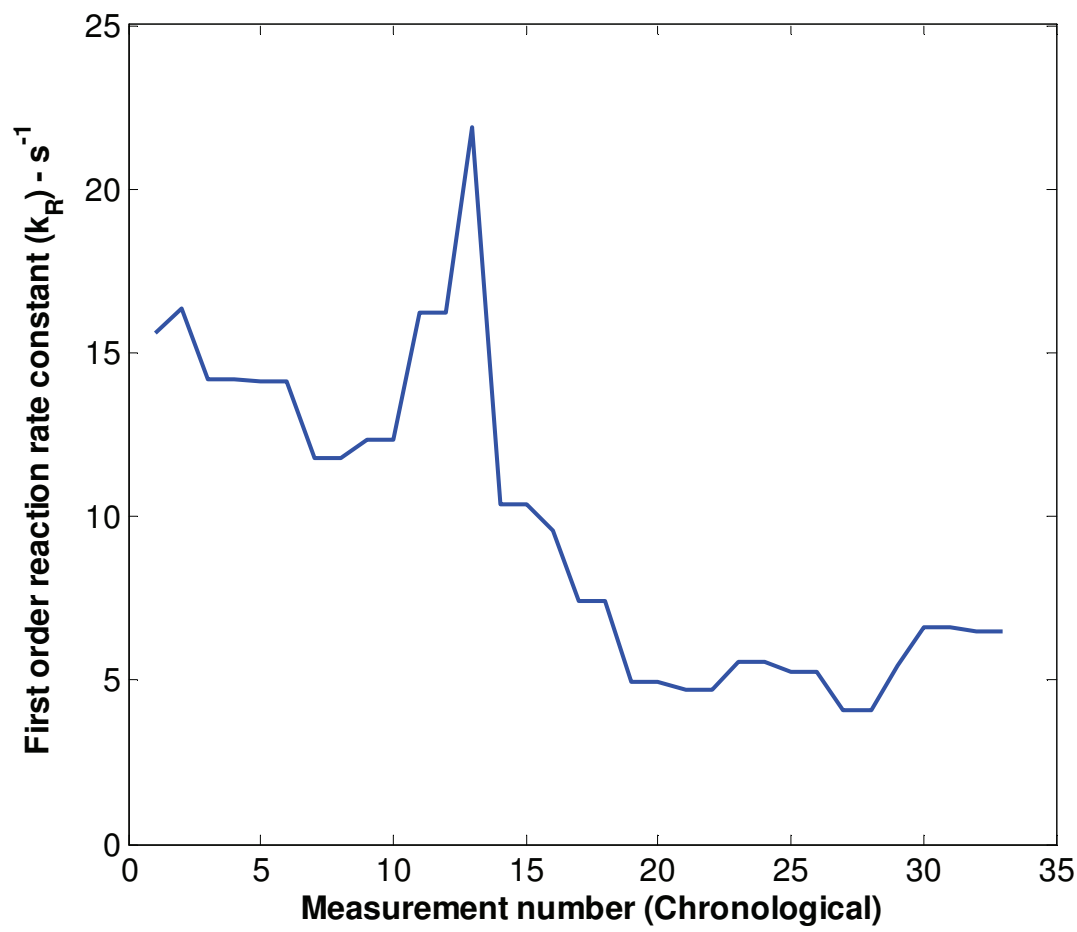

Figure 3: In-situ measurements of ozone decomposition rate constants $(\mathrm{kR})$ performed in the test PFR test reactor. 


\section{Results and discussion}

\subsection{Reactor performance}

Initial work to quantify reactor performance was done using an FCC catalyst in a pseudo2D column [37,38]. The Thompson et al. [25] model was used to do a best fit of the reactor performance over the velocity range and ascertain the mass transfer and axial dispersion. As shown by both Brink et al. [37] and Saayman [38], the shape of the fitted curve is dependent on the catalyst activity; therefore, if the activity changes significantly and the reactor is not fully mass transfer controlled, the method fails. Catalyst activity for sand is shown in Figure 3. Large changes and fluctuations in the activity are seen. These are caused by catalyst deactivation and humidity fluctuations respectively [39]. The humidity of the fluidizing air oscillated (1.5 h cycles), creating further activity fluctuations. This behaviour was caused by the compressor's chiller/dehumidifier.

Using FeSi catalyst an alternative method of interpretation was developed where data points could be evaluated individually [35]. The technique entails fitting the basic two-phase model to experimental data using the overall mass transfer coefficient (K0) as fitting parameter. The two-phase model is derived using mass balances for the individual bubblephase and emulsion-phase [21,31]. These mass balances result in 3 equations:

$$
\begin{aligned}
& C_{i}=u_{B} C_{i, B}+u_{E} C_{i, E} \\
& A_{\text {bed }} u_{B} \frac{d C_{i, B}}{d W}=-K_{O}\left(C_{i, B}-C_{i, E}\right) \\
& A_{\text {bed }} u_{E} \frac{d C_{i, E}}{d W}=-R_{i}\left(C_{E}\right)+K_{O}\left(C_{i, B}-C_{i, E}\right)
\end{aligned}
$$

The advantage of this approach is that only one parameter is fitted and all complexities of the Thompson et al. [25] model are avoided. It is important to understand when fitting this model to experimental data that $K_{O}$ will be an apparent parameter, similar to an apparent reaction rate constant. The value of $K_{0}$ will be influenced by hydrodynamic behaviour, which is not considered in the model; hence it is referred to as an "apparent overall mass transfer coefficient". Due to $K_{0}$ 's incorporation of hydrodynamic effects, it serves as a good indicator of the reactor's performance, irrespective of the catalytic activity.

Using the basic two-phase model, reactor conversion and catalyst activity at a superficial velocity, $K_{0}$ could be determined. Due to the implicit nature of the model, $K_{0}$ was fitted until the model conversion and the actual conversion matched within $\pm 1 \%$. Figure 4 shows $K_{0}$, the reactor performance, with the average of the three measurements at a superficial velocity. Reactor performance increased up to a superficial velocity of $0.45 \mathrm{~m} / \mathrm{s}$, after which a 


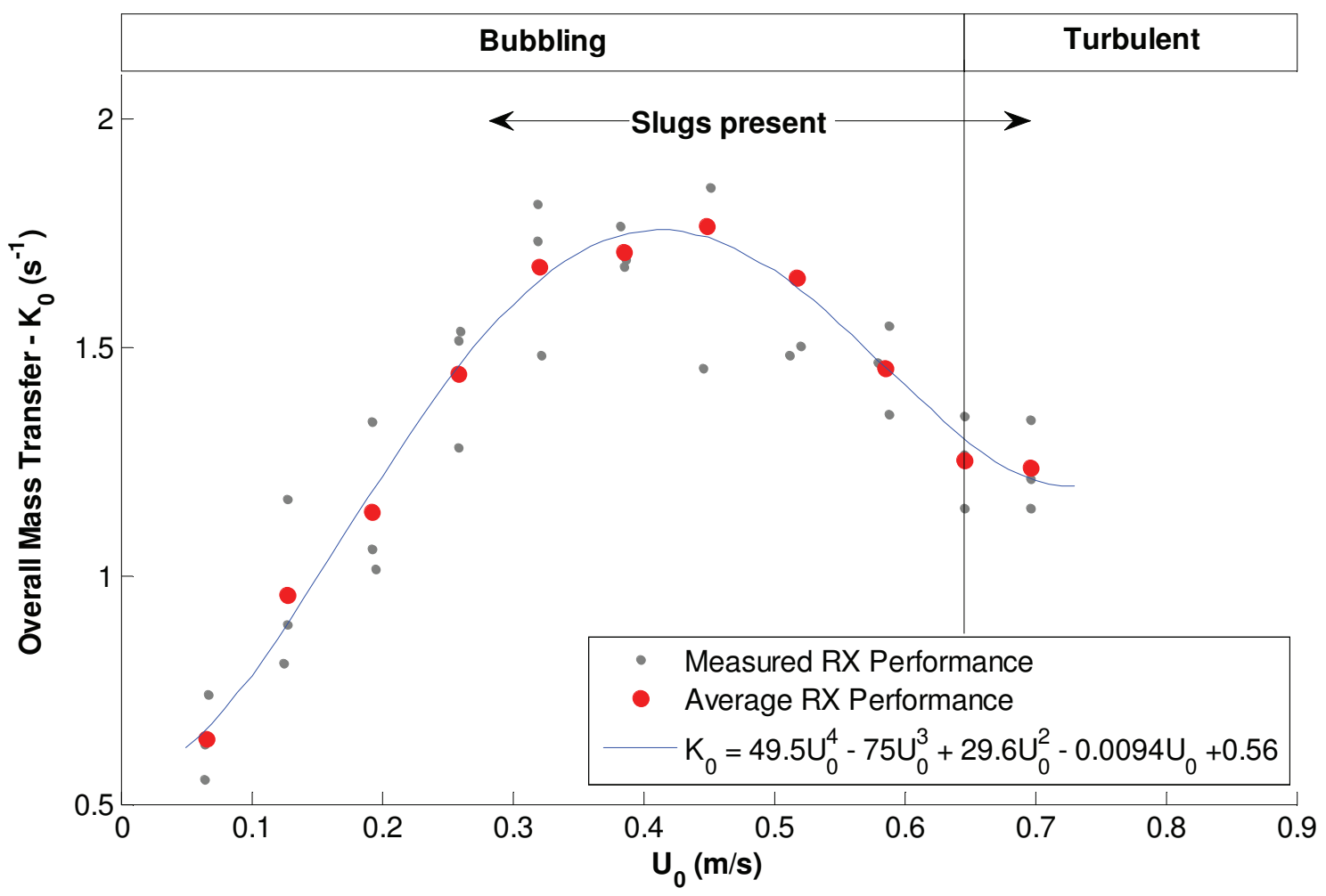

Figure 4: Reactor performance and fitted polynomial for interpolation. Experiments were repeated 3 times (grey) and the averages are shown in red. 
decreasing trend was observed. This behaviour cannot be explained directly by the observed slugging, as slugging started at approximately $0.25 \mathrm{~m} / \mathrm{s}$ and further exploration is required to address the issue (see section 3.2 and 3.3). For integration between the reaction measurements and the XRT measurements, a fit is required. As mentioned the hydrodynamic parameters were measured using an XRT setup with the same sand particles and a $140 \mathrm{~mm}$ column. Details on that setup and results of the investigation were already published $[32,33]$. Each investigation was performed at different superficial velocities and interpolation of reactor performance will be required. A fourth-order polynomial was used, as fourth order accurately preserves the shape. Excessive extrapolation outside the velocity range of $0.06 \mathrm{~m} / \mathrm{s}$ to $0.705 \mathrm{~m} / \mathrm{s}$ is not recommended.

\subsection{Hydrodynamics}

This section compares and confirms the hydrodynamic similarity between the reaction setup and the XRT setup. The transition between the bubbling and turbulent fluidization flow regimes was determined using the standard deviation of pressure fluctuations technique [5]. When using absolute pressure measurements, a clear trend in the standard deviation could not be found. However, the differential pressure measurements between the 20 and $40 \mathrm{~cm}$ pressure probes did show a clear trend, as seen in Figure 5. The standard deviation of pressure fluctuations of both the reaction and the XRT column are shown. $U_{c}$ was the same for both columns at $0.65 \mathrm{~m} / \mathrm{s}$. The XRT values are lower since these were determined using an absolute pressure signal and not a differential pressure signal.

The non-intrusive technique of Van der Schaaf et al. [40] was used for monitoring bubble behaviour in the reaction setup. This technique makes use of two pressure probes, one probe at the distributor and the second at a height in the bed where bubble measurement is desired. The Power Spectral Densities (PSDs) of both pressure probe signals are compared and the incoherence of the two signals relative to each other is calculated. The standard deviation of this incoherence $\left(\sigma_{i}\right)$ is a measure of the average bubble/void height. Van der Schaaf et al. [40] proved that relative bubble sizes and slug lengths can be determined using this technique. The magnitude of the effects that fines have on bubble sizes was observed by Beetstra et al. [41] using $\sigma_{i}$. Figure 6 shows good agreement exists between $\sigma_{i}$, measured in the reaction setup and the average void length, measured in the XRT setup. Both measurements were at $200 \mathrm{~mm}$ above the distributor in the respective setups. At $0.25 \mathrm{~m} / \mathrm{s}$ a 


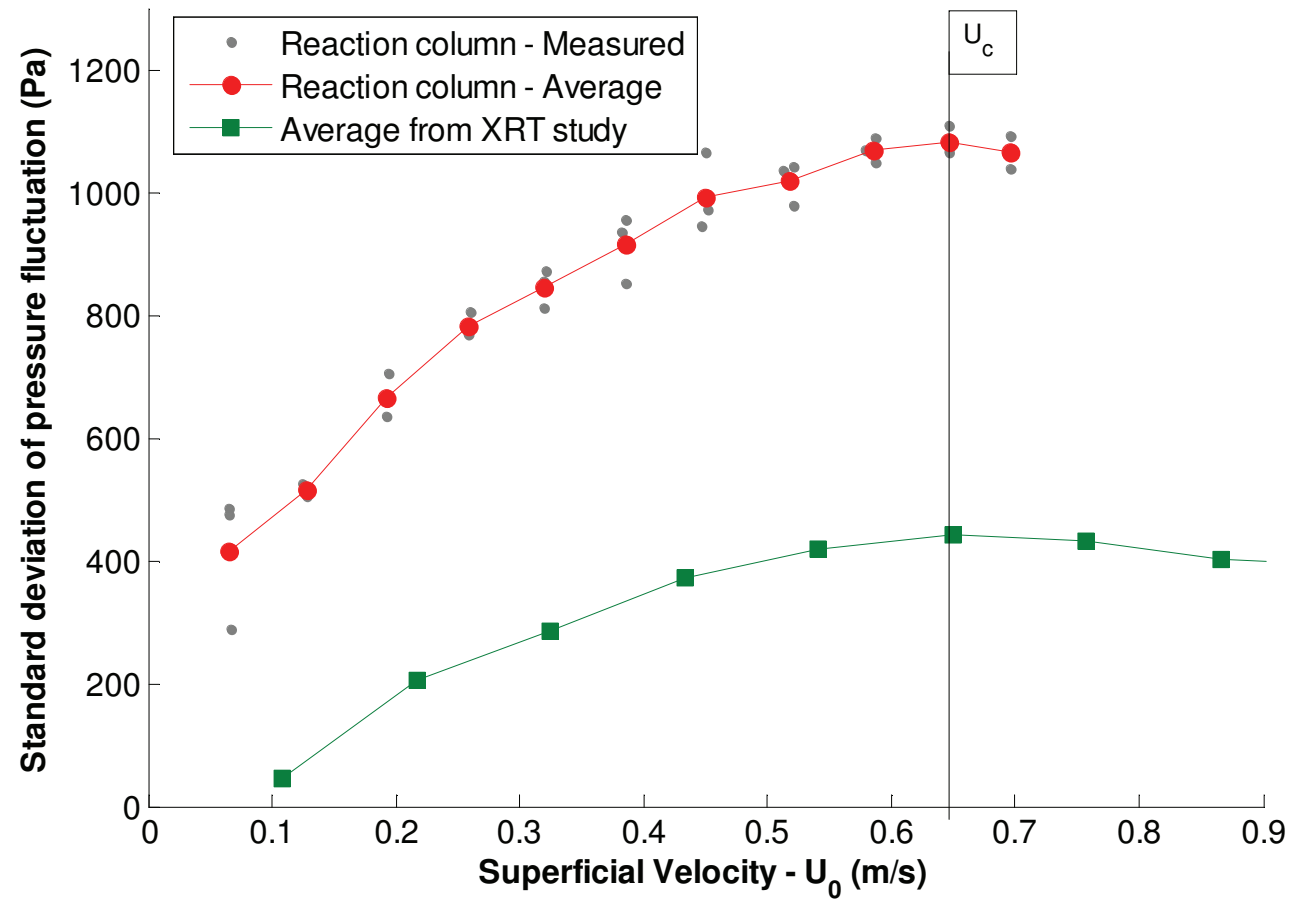

Figure 5: Bubbling to turbulent regime transition confirmed to be at $0.65 \mathrm{~m} / \mathrm{s}$ for both setups. 


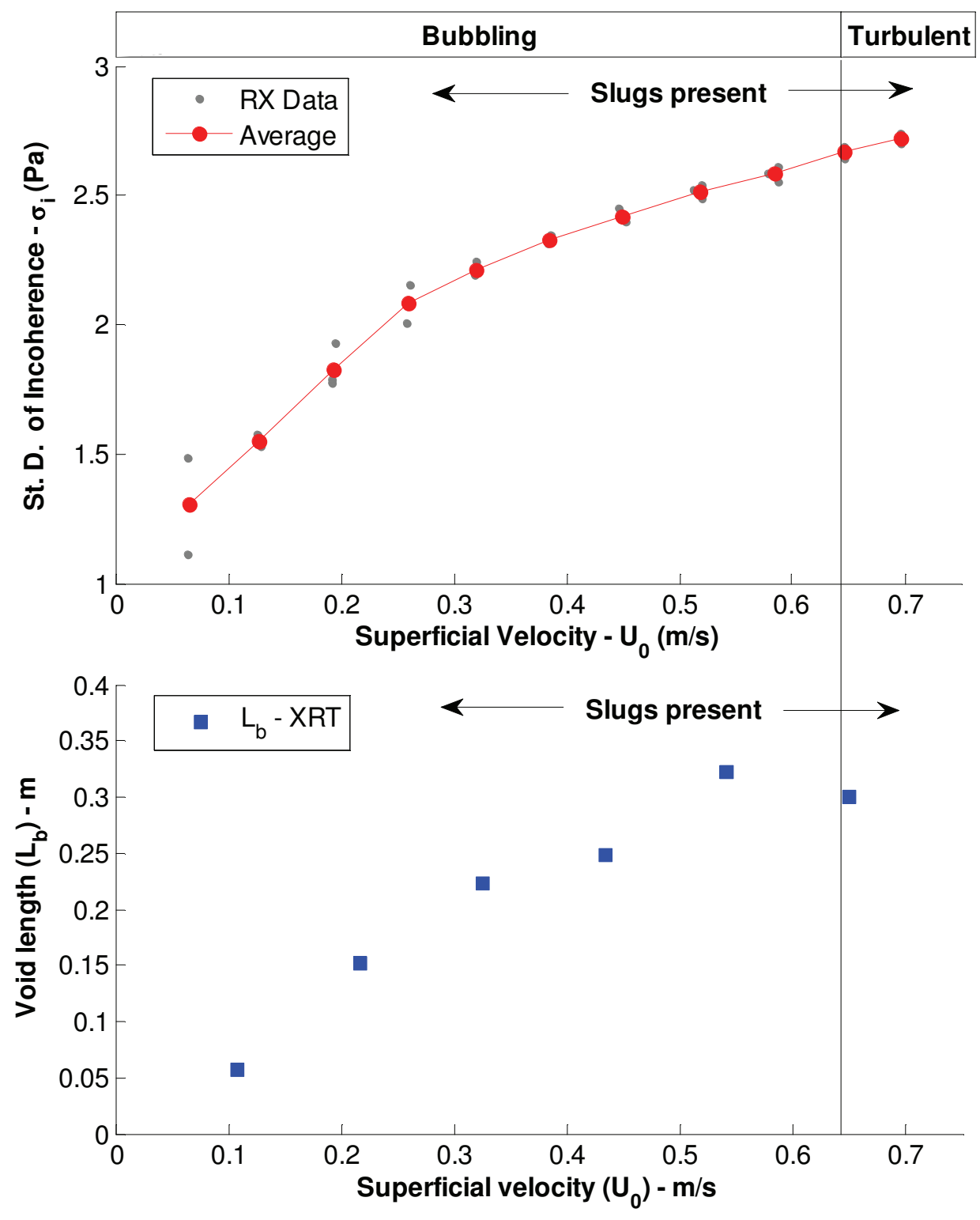

Figure 6: Relative shape agreement between measured standard deviation of incoherence in the reaction setup and the void length, determined using the XRT setup. The standard deviation of incoherence is a measure of the void length. 
gradient change occurs due to slug formation. This result is most likely due to the fact that the particle densities and sizes were the same. It can therefore be concluded that the ozone activation treatment of the particles did not influence the hydrodynamic behaviour.

\subsection{Link between reactor performance and hydrodynamics}

Insight into the reactor performance can be gained using the hydrodynamic information from XRT. The following parameters of individual bubbles were measured using the XRT method:

- Void volumes $-V_{b}$

- Void lengths $-L_{b}$

- Void rise velocities $-U_{b}$

- Cross-sectional solids concentration $-\Phi_{0}$

Assuming the bubble contains negligible solids, the voids fraction is:

$$
\psi_{B}=\frac{\Phi_{m f}-\Phi_{0}}{\Phi_{m f}}
$$

A cylindrical shape approximates voids more accurately than a spherical shape for this system [32,33]; therefore, the external bubble area per bubble volume can be calculated as follows:

$$
\begin{aligned}
& d_{b(C y l)}=\sqrt{\frac{4 V_{b}}{\pi L_{b}}} \\
& A_{b(C y l)}=2 *\left\{\frac{\pi}{4}\left(d_{b(C y l)}\right)^{2}\right\}+\pi L_{b} d_{b(C y l)} \\
& a_{I}=\frac{A_{b}}{V_{b}}
\end{aligned}
$$

Lastly, the terminal bubble rise velocity $\left(U_{b r}\right)$ can be calculated from:

$$
U_{b r}=U_{b}+U_{m f}-U_{o}
$$

The hydrodynamic considerations will be based on parameter averages calculated over the height of the reactor. This is because $K_{0}$ is an averaged parameter of the reactor. No single parameters showed a turning behaviour and it is reasonable to assume that a combination of parameters is required to explain the trend. From the literature it is known that rise velocities are linked to specific mass transfer rates. Foka et al. [30] used the superficial velocity of which the rise velocity is a function. $U_{0}$ will therefore also be considered alongside the other measured hydrodynamic parameters. Let $\mathrm{K}_{0}$ be proportional to a power law relationship of the measured variables $a_{1}, \psi_{B}, \Phi_{0}$ and $U_{0}$ : 


$$
K_{0} \propto\left(a_{I}^{k} \psi_{B}^{l} \Phi_{0}^{m} U_{0}^{n}\right)
$$

The Levenberg-Marquardt minimization algorithm (FSOLVE) of Matlab® was used (with $\mathrm{k}, \mathrm{l}, \mathrm{m}$ and $\mathrm{n}$ as the numbers to be minimized) in order to find a correlation between $\mathrm{K}_{0}$ and the parameters $a_{I}, \psi_{B}, \Phi_{0}$ and $U_{0}$, the following combination had the best agreement with $\mathrm{K}_{0}-$ $\mathrm{k}=0.936 ; 1=1.985 ; \mathrm{m}=-2.064 ; \mathrm{n}=-0.992$. These numbers are very close to whole numbers and it was found that the whole numbers resulted in an almost exact residual value:

$$
K_{0} \propto \frac{a_{I}{ }^{1} \psi_{B}^{2}}{\phi_{0}{ }^{2} U_{0}{ }^{1}}
$$

Figure 7 shows this combination of parameters with $U_{0}$ and the reactor performance with $U_{0}$. For both a turn is observed at $0.45 \mathrm{~m} / \mathrm{s}$.

\subsection{Specific interphase mass transfer}

The ideally structured and well-behaved voids of low velocity low-interaction bubbling beds differ considerably from the chaotic structures and behaviours at higher operating velocities. The mass transfer nature of $K_{0}$ is investigated by means of the specific interphase mass transfer coefficient $\left(k_{b e}\right)$. By taking into account the hydrodynamics of the reactor, the $K_{0}$ parameter can be converted to the generally used area-specific mass transfer coefficient $\left(k_{b e}\right) . K_{0}$ should be multiplied by the solids concentrations and divided by the specific bubble area:

$$
k_{b e}=\frac{K_{O} \Phi_{0}}{\psi_{B} a_{i}}
$$

It needs to be kept in mind that three hydrodynamic elements are assumed to have negligible influence on conversion when using the basic two-phase model:

- Solids content in the total disengagement height (TDH).

- Solids content in the bubbles.

- Gas flow in the emulsion phase is at $U_{m f}$.

The effects of these elements are incorporated into $K_{0}$ and could bias the $k_{b e}$ value if they are not negligible. Two of the assumption could be addressed. The validity of the first assumption with regard to the TDH was addressed by measuring the reactor outlet solids concentration/entrainment. Even with an ideal PFR assumption and the freeboard model of Kunii and Levenspiel [42], the contribution to overall conversion was between 5\% and 10\% of the overall conversion value (relative to overall conversion). This is at the highest flow rate $(0.7 \mathrm{~m} / \mathrm{s})$, the worst case scenario since the freeboard contribution declines with decreasing 


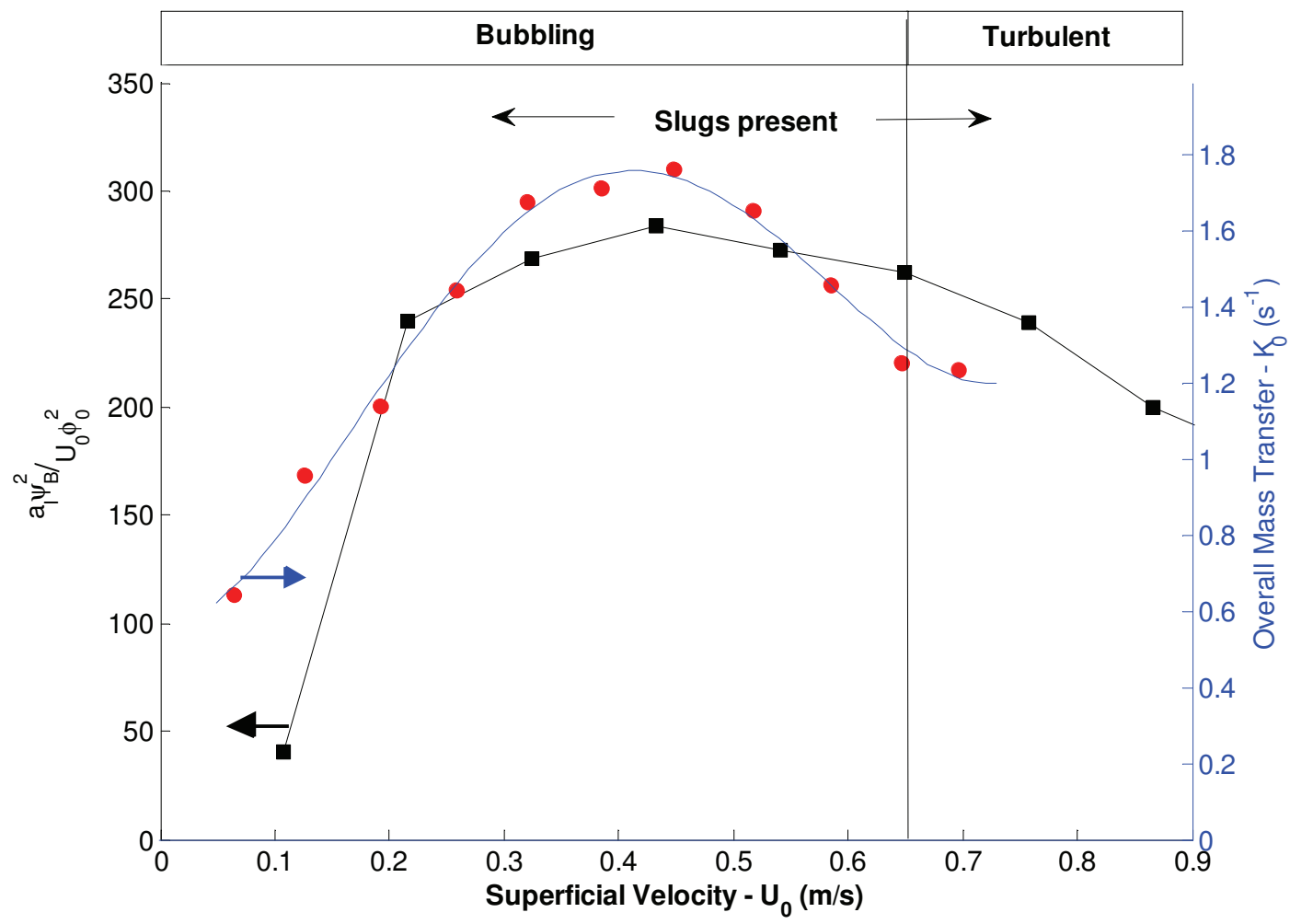

Figure 7: Combination of hydrodynamic parameters having the same trend as the reactor performance parameter KO. 
velocity. The TDH assumption was therefore deemed acceptable, especially when considering the bubbling regime to the onset of the turbulent regime. The assumption of negligible bubble solids content can be explored using the observed reactor performance results (Figure 4). Work by Sun and Grace [43] showed that bubble solids content increased with velocity. If the increased solids content was not negligible and significantly influenced $K_{0}$, then the decreasing trend beyond $0.45 \mathrm{~m} / \mathrm{s}$ would not be evident. From the measured parameters the bubble's solids content could not be determined directly. However, the results show indirectly that the possible contribution of solids in the bubble is of a secondary nature and the assumption is acceptable.

There are two types of mass transfer correlation in literature: the first is based on penetration theory and the second on boundary layer equations [13]. Literature correlations are tested to evaluate the applicability over the entire bubbling regime. The absolute value of $k_{b e}$ is dependent on the model assumptions, two of which have been deemed acceptable. The following discussion is concerned mainly with the observed trends with superficial velocity.

\subsubsection{Penetration theory}

In penetration theory $k_{b e}$ is generally a linear function of $\left(U_{b r} / d_{b}\right)^{1 / 2} \cdot d_{b}$ represents the void height; it can therefore be replaced by $L_{b}$. Considering Sit and Grace:

$$
k_{b e}=\frac{1}{3} U_{m f}+\left(\frac{4 D_{m} \varepsilon_{m f} U_{b r}}{\pi D_{b}}\right)^{\frac{1}{2}}
$$

The absolute correlation does not give a quantitatively good prediction, as seen in Figure 8(A-i). Hence, the constants in the correlation equation are combined:

$$
k_{b e}=c_{p t}+m_{p}\left(\frac{U_{b r}}{L_{b}}\right)^{\frac{1}{2}}
$$

$c_{p t}$ and $m_{p}$ represent all the constants. Using experimentally determined $k_{b e}$ and the XRT measurements for $U_{b r}$ and $L_{b}$ over the entire velocity range of $0.11 \mathrm{~m} / \mathrm{s}$ to $0.76 \mathrm{~m} / \mathrm{s}$, the best fit values for $c_{p t}$ and $m_{p}$ were determined:

$$
k_{b e}=-0.0265+0.0245\left(\frac{U_{b r}}{L_{b}}\right)^{\frac{1}{2}}
$$

Higher velocity $k_{b e}$ values and possible experimental error caused the negative value of $c_{p}$. Figure 8(A-i) shows the prediction of this equation using XRT data compared with the measured $k_{b e}$ using the reactor performance data. The scatter in correlation is due to the scatter in the experimentally determined values for $U_{b r}$ and $L_{b}$. The absolute percentage error 

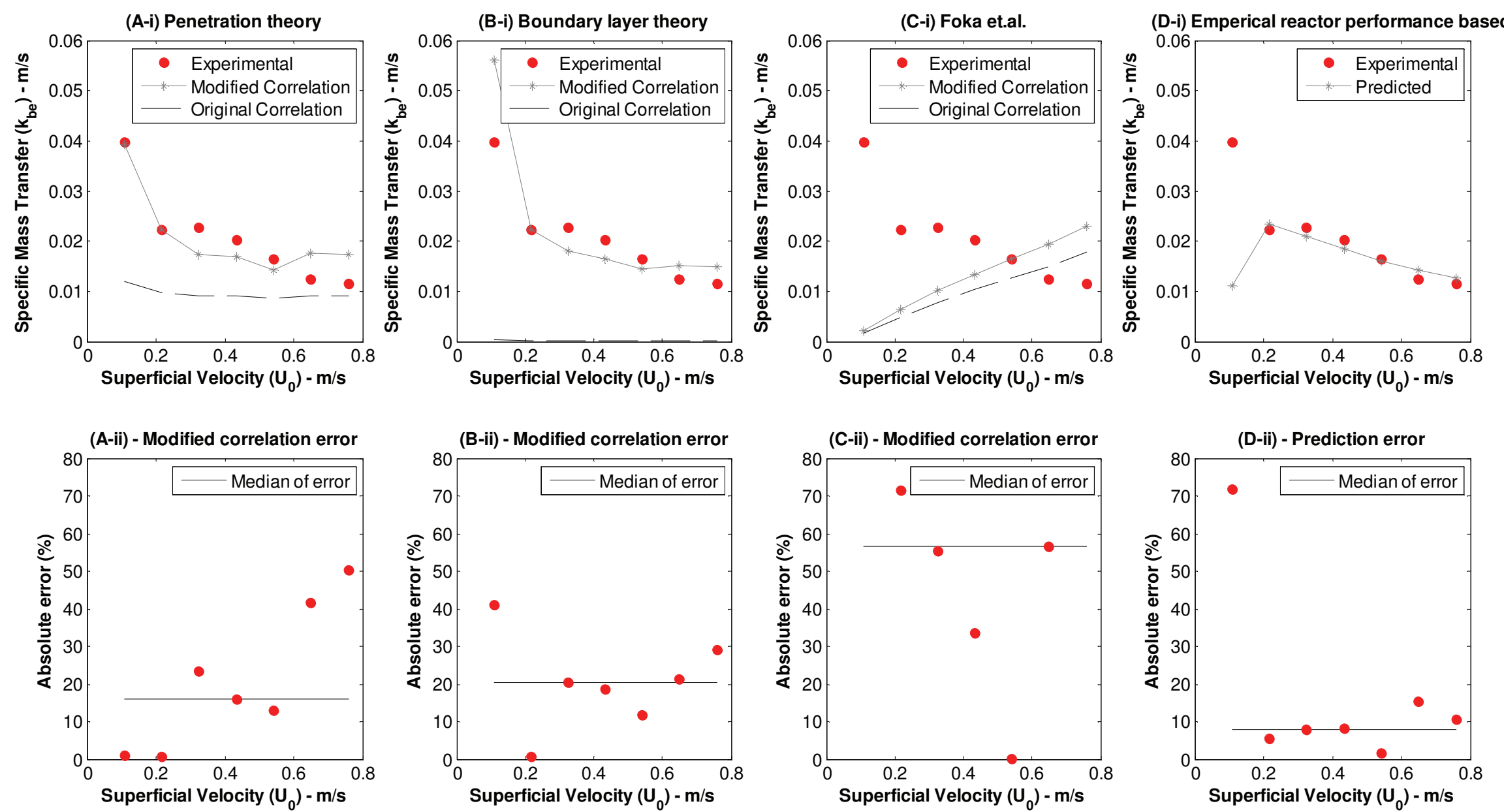

Figure 8: Predicted specific mass transfer compared with the measured specific mass transfer based on several theories and correlations. The error made in the modified correlation prediction is shown. 
is shown in Figure 8(A-ii); the line indicates the median error over the entire velocity range. For the entire velocity range the fit is not ideal; however, for the lower velocities $\left(U_{d} / U_{c}<0.34\right)$ the error is almost zero. This suggests that the mechanism of mass transfer proposed by penetration theory is only valid for low-interaction bubbling reactors.

\subsubsection{Boundary layer theory}

Two boundary layer correlations are tested, namely Partridge and Rowe [13] and Foka et al. [30]. Foka et al. developed their correlation based on bubbling and turbulent regime data. The correlation by Partridge and Rowe is considered first:

$$
\frac{k_{b e} a_{I} \psi_{B} D_{b}}{\varepsilon_{0} D_{m}}=2+0.69\left(\frac{\mu_{g}}{D_{m} \rho_{g}}\right)^{1 / 3}\left(\frac{\rho_{g} U_{b r} D_{b}}{\mu_{g}}\right)^{1 / 2}
$$

This correlation performs exceptionally poorly as seen in Figure 8(B-i). From general observations in the literature it is found that authors prefer penetration theory correlations. Following the same argument as above, the constants are combined and a linear equation is obtained:

$$
\frac{k_{b e} a_{I} \psi_{B} L_{b}}{1-\Phi_{0}}=c_{B}+m_{B}\left(U_{b r} L_{b}\right)^{\frac{1}{2}}
$$

$c_{B}$ and $m_{B}$ are the combinations of all the constants. Using experimentally determined $k_{b e}$ and the XRT measurements for $U_{b r}$ and $L_{b}$ over the entire velocity range of $0.11 \mathrm{~m} / \mathrm{s}$ to $0.76 \mathrm{~m} / \mathrm{s}$, the best fit values for $c_{B}$ and $m_{B}$ were determined:

$$
\frac{k_{b e} a_{I} \psi_{B} L_{b}}{1-\Phi_{0}}=0.3179+0.0366\left(U_{b r} L_{b}\right)^{\frac{1}{2}}
$$

Figure $8(\mathrm{~B}-\mathrm{i})$ and (B-ii) shows the results. Relative to penetration theory, the predicted trend agreement is worse.

The correlation by Foka et al. has a direct proportionality and does not perform well:

$$
k_{b e} a_{I}=1.631 S c^{0.37} U_{0}
$$

The process of linearization was repeated, except that a linear equation was used which goes through the origin:

$$
k_{b e}=1.8997\left(\frac{U_{0}}{a_{I}}\right)
$$

Figure $8(\mathrm{C}-\mathrm{i})$ shows that the original correlation and the modified correlation do not differ significantly. This is due to fewer degrees of freedom in the number of fitting parameters. Although the correlation was designed to include the entire bubbling and turbulent regime, 
the errors are extremely large as shown in Figure $8(\mathrm{C}-\mathrm{ii})$. Bi et al. mentioned that this correlation had not been extensively validated and should be used with caution [5].

\subsubsection{Empirical correlation}

Based on observations in Figure 7, it is proposed to correlate $k_{b e}$ and $\psi_{B} /\left(\Phi_{0} U_{0}\right)$. This parameter is referred to as $\beta$ :

$$
\begin{aligned}
& K_{0} \propto \frac{a_{I}{ }^{1} \psi_{B}{ }^{2}}{\phi_{0}{ }^{2} U_{0}{ }^{1}} \\
& \frac{K_{0}\left(\phi_{0}\right)}{\left(a_{I} \psi_{B}\right)} \propto \frac{\psi_{B}}{\phi_{0} U_{0}} \\
& k_{b e} \propto \frac{\psi_{B}}{\phi_{0} U_{0}}=\beta
\end{aligned}
$$

Performing a linear fit through the origin gives:

$$
k_{b e}=0.00568 \beta
$$

Figure 8(D-i) shows this equation's prediction compared with the measured values and Figure 8 (D-ii) shows the error. At $8 \%$ the lowest median of errors over the velocity range is obtained. This combination of hydrodynamic parameters fails to predict at the lowest velocity were ideal bubbling occurs. For the rest of the range $\left(U_{0} / U_{c}>0.17\right)$ good correlation is observed. The ideally structured and well-behaved voids of low-interaction bubbling beds differ considerably from the chaotic structures and behaviours at higher operating velocities, a single mass transfer correlation suitable for all velocity could therefore not be found. A change in mass transfer behaviour occurs around $U_{0} / U_{c}=0.25$.

\section{Conclusions}

A fast X-Ray Tomography (XRT) setup and a reaction setup with close to identical column sizes and packing were used in this investigation. Reactor performance was quantified using a basic two-phase model and an apparent overall mass transfer parameter $\left(K_{0}\right)$. This revised method of analysis and quantification eliminated the need to stabilize the activity of the ozone decomposition catalyst. As superficial velocity increased, $K_{0}$ (the reactor performance) increased up to $U_{0}=0.45 \mathrm{~m} / \mathrm{s}$, after which a decreasing trend was observed. The performance continued to decrease, reaching a plateau with superficial velocity at the bubbling-turbulent regime transition. The hydrodynamic measurements from XRT were used 
to evaluate the mass transfer characteristics of $K_{0}$. The observed trend could be correlated using the following combination of hydrodynamic parameters:

$$
K_{0} \propto \frac{a_{I}^{1} \psi_{B}^{2}}{\phi_{0}^{2} U_{0}{ }^{1}}
$$

Specific interphase mass transfer $\left(k_{b e}\right)$ was investigated and it was found there is a distinct difference between low-interaction bubbling regime behaviour and high-interaction bubbling regime behaviour. Using the relationship between $K_{0}$ and $k_{b e}$, the above equation was rewritten and an empirical correlation is suggested for $k_{b e}$ :

$$
k_{b e} \propto \frac{\psi_{B}}{\phi_{0} U_{0}}=\beta
$$

$\beta$ gave the best fit for the entire velocity range with an average error of $8 \%$, although it is not recommended for $\mathrm{U}_{0} / \mathrm{U}_{\mathrm{c}}<0.17$. From a comparison of the classical approaches of penetration theory and boundary layer theory it was found that penetration theory performed better at low velocities $\left(U_{0} / U_{c}<0.34\right)$. The boundary between the low-interaction and high-interaction bubbling regimes occurs around a $U_{d} U_{c}$ of 0.25 for this system.

\section{Nomenclature}

$\mathrm{A}_{\mathrm{b}(\mathrm{Cyl})}$ External surface area of cylindrical bubble $\quad\left[\mathrm{m}^{2}\right]$

$A_{\text {bed }}$ Cross sectional area of the reactor $\left[\mathrm{m}^{2}\right]$

a Inter-phase transfer surface $\left[\mathrm{m}^{-1}\right]$

$\mathrm{C}_{\mathrm{i}, \mathrm{B}}$ Concentration in bubble $\left[\mathrm{mol} / \mathrm{m}^{3}\right]$

$\mathrm{C}_{\mathrm{i}, \mathrm{E}}$ Concentration in emulsion $\left[\mathrm{mol} / \mathrm{m}^{3}\right]$

$\mathrm{C}_{\mathrm{i}}$ Gas concentration of species I $\quad\left[\mathrm{kmol} / \mathrm{m}^{3}\right]$

$\mathrm{D}_{\mathrm{b}} \quad$ Spherical-Volume equivalent bubble diameter $\quad[\mathrm{m}]$

$\mathrm{D}_{\mathrm{m}} \quad$ Gas diffusion coefficient $\left[\mathrm{m}^{2} / \mathrm{s}\right]$

$\mathrm{d}_{\mathrm{b}(\mathrm{Cyl})}$ Base diameter of cylindrical bubble $\quad[\mathrm{m}]$

$\mathrm{d}_{\mathrm{p}} \quad$ Sauter mean particle diameter $[\mathrm{m}]$

$\mathrm{K}_{0} \quad$ Overall interphase mass transfer (catalyst volume based) $\quad\left[\mathrm{s}^{-1}\right]$

$\mathrm{L}_{\mathrm{b}} \quad$ Length/height of voids $\quad[\mathrm{m}]$

$\mathrm{k}_{\mathrm{be}} \quad$ Specific interphase mass transfer (bubble to emultion) $\quad[\mathrm{m} / \mathrm{s}]$

$\mathrm{k}_{\mathrm{R}} \quad$ Reaction rate constant (catalyst volume based) $\quad\left[\mathrm{s}^{-1}\right]$

Q Volumetric flow rate in test reactor $\left[\mathrm{m}^{3} / \mathrm{s}\right]$

$\mathrm{R}_{\mathrm{i}} \quad$ Reaction rate as a function of concentration $\left[\mathrm{s}^{-1}\right]$ 
Sc Schmidt number $\left(\mu /\left(\rho_{\mathrm{g}} . \mathrm{D}_{\mathrm{m}}\right)\right)$

$\mathrm{U}_{\mathrm{b}} \quad$ Average bubble velocity, relative to distributor $\quad[\mathrm{m} / \mathrm{s}]$

$\mathrm{u}_{\mathrm{B}} \quad$ Bubble phase reactor model gas velocity [m/s]

$\mathrm{U}_{\mathrm{br}} \quad$ Terminal rise velocity of a single bubble $\quad[\mathrm{m} / \mathrm{s}]$

$U_{c} \quad$ Onset of turbulent regime velocity $\quad[\mathrm{m} / \mathrm{s}]$

$\mathrm{u}_{\mathrm{E}} \quad$ Emulsion phase reactor model gas velocity $[\mathrm{m} / \mathrm{s}]$

$\mathrm{U}_{\mathrm{mf}}$ Minimum fluidization velocity $[\mathrm{m} / \mathrm{s}]$

$\mathrm{U}_{0} \quad$ Operating velocity $[\mathrm{m} / \mathrm{s}]$

$\mathrm{V}_{\mathrm{b}} \quad$ Volume of bubble/void $\left[\mathrm{m}^{3}\right]$

W Solids volume of catalyst $\left[\mathrm{m}^{3}\right]$

X Conversion [-]

Greek letters

$\beta \quad$ Empirical mass transfer parameter $\left(\psi_{\mathrm{B}} /\left(\Phi_{0} \mathrm{U}_{0}\right)\right) \quad[\mathrm{s} / \mathrm{m}]$

$\varepsilon_{\mathrm{mf}} \quad$ Gas volume fraction at minimum fluidization $[-]$

$\rho_{\mathrm{b}} \quad$ Bulk density $\quad\left[\mathrm{kg} / \mathrm{m}^{3}\right]$

$\rho_{\mathrm{p}} \quad$ Particle density $\quad\left[\mathrm{kg} / \mathrm{m}^{3}\right]$

$\rho_{\mathrm{g}}$ Gas density $\quad\left[\mathrm{kg} / \mathrm{m}^{3}\right]$

$\begin{array}{lll}\mu_{\mathrm{g}} & \text { Gas viscosity } & \text { [Pa.s] }\end{array}$

$\begin{array}{lll}\sigma_{\mathrm{i}} & \text { Standard deviation of incoherence } & {[\mathrm{Pa}]}\end{array}$

$\Phi_{0} \quad$ Solids volume fraction $(1-\varepsilon) \quad[-]$

$\Phi_{\mathrm{mf}} \quad$ Solids fraction of incipiently fluidized bed [-]

$\psi_{\mathrm{B}} \quad$ Bubble phase volume fraction

\section{References}

[1] J. Saayman, W. Nicol, Demonstrating the effect of interphase mass transfer in a transparent fluidized bed reactor, Chemical Engineering Education. 45 (2011) 178183.

[2] J.R. van Ommen, J.M. Valverde, R. Pfeffer, Fluidization of nanopowders: a review., Journal of Nanoparticle Research. 14 (2012) 737.

[3] D.J. Duvenhage, T. Shingles, Synthol reactor technology development, Catalysis Today. 71 (2002) 301-305. 
[4] A.P. Steynberg, R.L. Espinoza, B. Jager, A.C. Vosloo, High temperature FischerTropsch synthesis in commercial practice, Applied Catalysis A: General. 186 (1999) $41-54$.

[5] H.T. Bi, N. Ellis, I.A. Abba, J.R. Grace, A state-of-the-art review of gas-solid turbulent fluidization, Chemical Engineering Science. 55 (2000) 4789-4825.

[6] P.N. Rowe, B.A. Partridge, E. Lyall, G.M. Ardran, Bubbles in Fluidized Beds, Nature. 195 (1962) 278-279.

[7] P.N. Rowe, B.A. Partrige, Gas flow through bubbles in a fluidized bed - I Flow through an ideal bubble, Chemical Engineering Science. 18 (1963) 511-524.

[8] J.F. Davidson, D. Harrison, The behaviour of a continuously bubbling fluidised bed, Chemical Engineering Science. 21 (1966) 731-738.

[9] J.F. Davidson, D. Harrison, Fluidized Particles, 1st ed., The Syndics of the Cambridge University Press, 1963.

[10] M.J. Lockett, J.F. Davidson, D. Harrison, On the two-phase theory of fluidization, Chemical Engineering Science. 22 (1967) 1059-1066.

[11] G.K. Stephens, R.J. Sinclair, O.E. Potter, Gas Exchange between Bubbles and Dense Phase in a Fluidised Bed, Powder Technology. 1 (1967) 157-166.

[12] K. Godard, J.F. Richardson, Distribution of gas flow in a fluidised bed, Chemical Engineering Science. 23 (1968) 660.

[13] A.A.H. Drinkenburg, K. Rietema, Gas transfer from bubbles in a fluidized bed to the dense phase-I. Theory, Chemical Engineering Science. 27 (1972) 1765-1774.

[14] C. Chavarie, J.R. Grace, Interphase Mass Transfer in a Gas-Fluidized Bed, Chemical Engineering Science. 31 (1975) 741-749.

[15] S.P. Sit, J.R. Grace, Interphase Mass Transfer in an Aggregative Fluidized Bed, Chemical Engineering Science. 33 (1978) 1115-1122.

[16] S.P. Sit, J.R. Grace, Effect of Bubble Interaction on Interphase Mass Transfer in Gas Fluidized Beds, Chemical Engineering Science. 36 (1981) 327-335.

[17] C. Chavarie, J.R. Grace, Performance Analysis of a Fluidized Bed Reactor. II. Observed Reactor Behavior Compared with Simple Two-Phase Models, Industrial \& Engineering Chemistry Fundamentals. 14 (1975) 79-86.

[18] C. Chavarie, J.R. Grace, Performance Analysis of a Fluidized Bed Reactor. I. Visible Flow Behavior, Industrial \& Engineering Chemistry Fundamentals. 14 (1975) 75-79. 
[19] C. Chavarie, J.R. Grace, Performance analysis of a fluidized bed reactor. III. Modification and extension of conventional two-phase models, Industrial \& Engineering Chemistry Fundamentals. 14 (1975) 86-91.

[20] J.R. Grace, Generalized Models for Isothermal Fluidized Bed Reactors, in: L.K. Doraiswamy (Ed.), Recent Advances in the Engineering Analysis of Chemically Reacting Systems, New Delhi. Wiley Eastern, 1984: pp. 237-255.

[21] D. Kunii, O. Levenspiel, Fluidized reactor models. 1. For bubbling beds of fine, intermediate, and large particles. 2. For the lean phase: freeboard and fast fluidization, Industrial \& Engineering Chemistry Research. 29 (1990) 1226-1234.

[22] D. Kunii, O. Levenspiel, Entrainment of solids from fluidized beds I. Hold-up of solids in the freeboard II. Operation of fast fluidized beds, Powder Technology. 61 (1990) 193-206.

[23] I.A. Abba, J.R. Grace, H.T. Bi, Spanning the Flow Regimes : Generic Fluidized-Bed Reactor Model, AIChE Journal. 49 (2003) 1838-1848.

[24] J. Chaouki, A. Gonzalez, C. Guy, D. Klvana, Two-phase model for a catalytic turbulent fluidized-bed reactor: Application to ethylene synthesis, Chemical Engineering Science. 54 (1999) 2039-2045.

[25] M.L. Thompson, H. Bi, J.R. Grace, A generalized bubbling/turbulent fluidized-bed reactor model, Chemical Engineering Science. 54 (1999) 3-10.

[26] R. Jafari, R. Sotudeh-Gharebagh, N. Mostoufi, Performance of the wide-ranging models for fluidized bed reactors, Advanced Powder Technology. 15 (2004) 533-548.

[27] W. Wu, P.K. Agarwal, The Effect of Bed Temperature on Mass Transfer Fluidized Bed, The Canadian Journal of Chemical Engineering. 81 (2003) 940-948.

[28] G. Sun, J.R. Grace, The Effect of Particle Size Distribution on the Performance of a Catalytic Fluidized Bed Reactor, Chemical Engineering Science. 45 (1990) 21872194.

[29] J.B.L.M. Campos, O.D.S. Mota, A.M.F.R. Pinto, Measurement of Mass Transfer between the Bubble and Dense Phases in a Fluidized Bed Combustor, Combustion and Flame. 116 (1998) 105-119.

[30] M. Foka, J. Chaouki, C. Guy, D. Klvana, Gas phase hydrodynamics of a gas-solid turbulent fluidized bed reactor, Chemical Engineering Science. 51 (1996) 713-723.

[31] D. Kunii, O. Levenspiel, Fluidization Engineering, 2nd ed., Butterworth-Heinemann, 1991. 
[32] J. Saayman, J.R. Van Ommen, R.F. Mudde, E.C. Wagner, W. Nicol, Fluidization Regimes Characterized Using a Fast X-Ray Tomography Setup, in: F. Berruti (Ed.), The 14th International Conference on Fluidization - From Fundamentals to Products, ECI Symposium Series, 2013.

[33] J. Saayman, W. Nicol, J. R. van Ommen, R.F. Mudde, Fast X-Ray Tomography for the Quantification of the Bubbling-, Turbulent- and Fast Fluidization- Flow Regimes and Void Structures, Chemical Engineering Journal. 234 (2013) 437-447.

DOI: http://dx.doi.org/10.1016/j.cej.2013.09.008

[34] C. Fan, X. Bi, W. Lin, W. Song, Mass transfer and reaction performance of the downer and its hydrodynamic explanation, The Canadian Journal of Chemical Engineering. 86 (2008) 436-447.

[35] J. Saayman, N. Ellis, W. Nicol, Fluidization of high-density particles: The influence of fines on reactor performance, Powder Technology. 245 (2013) 48-55.

[36] C. Fan, Y. Zhang, X. Bi, W. Song, W. Lin, L. Luo, Evaluation of downer reactor performance by catalytic ozone decomposition, Chemical Engineering Journal. 140 (2008) 539-554.

[37] H.G. Brink, J. Saayman, W. Nicol, Two Dimensional Fluidised Bed Reactor: Performance of a Novel Multi-Vortex Distributor, Chemical Engineering Journal. 175 (2011) 484-493.

[38] J. Saayman, Bubbling to Turbulent Regime Transition in a 2D Catalytic Fluidized Bed Reactor, University of Pretoria, 2009.

[39] B. Dhandapani, S.T. Oyama, Gas phase ozone decomposition catalysts, Applied Catalysis B: Environmental. 11 (1997) 129-166.

[40] J. Van der Schaaf, J.C. Schouten, F. Johnsson, C.M. Van den Bleek, Non-intrusive determination of bubble and slug length scales in fluidized beds by decomposition of the power spectral density of pressure time series, International Journal of Multiphase Flow. 28 (2002) 865-880.

[41] R. Beetstra, J. Nijenhuis, N. Ellis, J.R. Van Ommen, The Influence of the Particle Size Distribution on Fluidized Bed Hydrodynamics Using High-Throughput Experimentation, AIChE Journal. 55 (2009) 2013-2023.

[42] D. Kunii, O. Levenspiel, The KL reactor model for circulating fluidized beds, Chemical Engineering Science. 55 (2000) 4563-4570.

[43] G. Sun, J.R. Grace, Experimental determination of particle dispersion in voids in a fluidized bed, Powder Technology. 80 (1994) 29-34. 